\title{
DETERMINAÇÃO CONDUTOMÉTRICA DE CLORIDRATO DE TETRACICLINA EM FORMULAÇÕES FARMACÊUTICAS
}

\author{
Enock José A. Goes Junior, Jakson S. Roeder e Jonatas G. da Silva* \\ Curso de Química, Universidade Católica de Brasília, 71966-700 Brasília - DF, Brasil
}

Recebido em 06/01/2017; aceito em 08/03/2017; publicado na web em 04/05/2017

\begin{abstract}
CONDUCTOMETRIC DETERMINATION OF TETRACYCLINE HYDROCHLORIDE IN PHARMACEUTICAL FORMULATIONS. In the present article it is described, a simple, precise, rapid and low-cost conductometric titration of tetracycline hydrochloride in pharmaceutical formulations using silver nitrate as titrant. The method is based on the precipitation of chloride ions derived from tetracycline hydrochloride with silver ions, yielding silver chloride precipitate and the conductance of the solution is measured as a function of the volume of titrant. The coefficient of variation for six successive measurements was $0.64 \%$ and no interferences were observed in the presence of common components of the pharmaceutical formulations. Recovery values from two samples, ranging from 99.0 to $105 \%$, were obtained. The method was applied for tetracycline hydrochloride determination in two pharmaceuticals formulations and these results are in good accordance with the declared values of manufacturer and an official method of the Brazilian Pharmacopoeia, based on spectrophotometric analysis, at a 95\% confidence level.
\end{abstract}

Keywords: conductometric titration; tetracycline hydrochloride; silver nitrate; pharmaceutical formulations.

\section{INTRODUÇÃO}

O cloridrato de tetraciclina (TCN) (Figura 1) pertence a um grupo de antibióticos que possui um largo espectro antibacteriano e atividade bacteriostática, além de uma boa atividade contra doenças agudas causadas por bactérias gram-positivas e gram-negativas. Devido a essas características, o TCN é um dos antibióticos mais utilizados no mundo para tratar doenças bacterianas em humanos (infecções urinárias, clamídia, e acne) e na medicina veterinária. ${ }^{1,2}$<smiles>CN(C)[C@H]1C(O)=C(C(N)=O)C(=O)[C@]2(O)C(O)=C3C(=O)c4c(O)cccc4[C@@](C)(O)[C@H]3C[C@H]12</smiles>

Figura 1. Estrutura química do cloridrato de tetraciclina

Diferentes métodos analíticos como espectrofotométrico, ${ }^{3,4}$ espectrofluorimétrico, ${ }^{5,6}$ cromatográfico, ${ }^{7-9}$ eletroforético, ${ }^{10,11}$ potenciométrico ${ }^{12,13} \mathrm{e}$ voltamétrico, ${ }^{14-16}$ foram descritos na literatura para a quantificação de TCN, em diferentes amostras como alimentícias, ambientais, biológicas e farmacêuticas. Para o doseamento de TCN em cápsulas a farmacopeia brasileira ${ }^{17}$ descreve os métodos espectrofotométrico e cromatográfico como oficiais. Entretanto, a maioria desses métodos apresenta algumas desvantagens, como tempo de análise longo, pré-tratamento da amostra e instrumentação de alto custo, tornando-os inadequados para as análises de rotina.

A titulação condutométrica é uma técnica analítica rápida e precisa que pode ser empregada nas análises de rotina, exigindo uma instrumentação simples e de baixo custo. Alguns exemplos do emprego de titulações condutométricas na quantificação de diferentes espécies químicas em formulações farmacêuticas podem ser encontrados na literatura. ${ }^{18-27} \mathrm{O}$ método titrimétrico é aceito como oficial pela

\footnotetext{
*e-mail: jonatasg@yahoo.com.br
}

farmacopeia brasileira ${ }^{17}$ para a quantificação de diferentes espécies químicas em formulações farmacêuticas.

Sartori e colaboradores ${ }^{18}$ empregaram a titulação condutométrica na determinação de cloridrato de fluoxetina (antidepressivo), em formulações farmacêuticas, utilizando-se o nitrato de prata como titulante. O método desenvolvido envolveu a formação de um sal insolúvel de cloreto de prata $(\mathrm{AgCl})$ pela reação entre o titulante nitrato de prata $\left(\mathrm{AgNO}_{3}\right)$ e o cloreto $(\mathrm{Cl})$ do cloridrato $(\mathrm{HCl})$ da molécula de fluoxetina. Neste trabalho os autores obtiveram recuperações do analito, em três amostras, variando de 95,3 a 105\%. O teste t pareado indicou que os resultados obtidos para o cloridrato de fluoxetina, em formulações farmacêuticas, utilizando-se o método condutométrico proposto e o método oficial, não apresentaram diferenças significativas, em um nível de confiança de $95 \%$. Em outro estudo, Sartori e colaboradores ${ }^{19}$ determinaram o teor de cloridrato de metformina (antidiabético) em formulações farmacêuticas empregando-se a titulação condutométrica e o $\mathrm{AgNO}_{3}$ como titulante. $\mathrm{O}$ método condutométrico proposto foi aplicado na determinação de cloridrato de metformina em três formulações farmacêuticas e os resultados obtidos foram concordantes, em um nível de confiança de 95\%, com os obtidos utilizando-se o método oficial da Farmacopeia Britânica. O procedimento adotado, utilizando-se a titulação condutométrica na quantificação dos cloridratos de fluoxetina e metformina em formulações farmacêuticas, mostrou-se simples, preciso, rápido e de baixo custo.

A titulação condutométrica também foi empregada por Caetano e colaboradores ${ }^{20}$ na determinação do cloridrato de verapamil (antiarrítmico) em formulações farmacêuticas, utilizando-se o $\mathrm{AgNO}_{3}$ como titulante. $\mathrm{O}$ coeficiente de variação obtido para seis análises sucessivas foi menor que $0,5 \%$ e não foram observadas interferências na presença dos componentes comuns nos comprimidos, como monofosfato de sódio, estearato de magnésio e lactose. Os autores obtiveram recuperações de cloridrato de verapamil, a partir de várias formulações farmacêuticas, variando de 97,1 a 102,8\%. Os resultados obtidos nas análises das formulações farmacêuticas foram concordantes com os valores declarados pelos fabricantes e com os obtidos utilizando-se o método oficial espectrofotométrico.

Nota-se que o desenvolvimento de um método alternativo simples, preciso, rápido e de baixo custo, para a análise de rotina de TCN em 
formulações farmacêuticas é importante devido à grande utilização deste antibiótico no tratamento de doenças bacterianas em humanos e animais. Neste contexto, o presente trabalho tem como objetivo propor um método empregando a titulação condutométrica como alternativa para a quantificação de TCN em formulações farmacêuticas.

\section{PARTE EXPERIMENTAL}

\section{Equipamentos}

As medidas condutométricas foram realizadas em triplicata, utilizando-se o condutivímetro DM 31 (Digimed $^{\circledR}$ ) e uma célula de condutividade DMC-010M (Digimed ${ }^{\circledR}, \mathrm{K}=1,0 \mathrm{~cm}^{-1}$ ) formada por dois discos de platina, a qual foi calibrada antes das medidas com solução padrão de condutividade $\left(1413 \mu \mathrm{S} \mathrm{cm}^{-1}\right)$. As soluções foram mantidas sob agitação constante a uma temperatura de $23^{\circ} \mathrm{C} \pm 1$ durante todas as medidas. A quantificação de TCN em formulações farmacêuticas, empregando-se o método de referência, ${ }^{17}$ foi realizada utilizando-se um espectrômetro Cary 50 (Varian $\left.{ }^{\circledR}\right)$ acoplado a um microcomputador. Todas as medidas de massa foram realizadas em balança analítica semi-micro $(\sigma \leq 0,05 \mathrm{mg})$ AUW220D (Shimadzu ${ }^{\circledR}$. As vidrarias volumétricas utilizadas foram previamente calibradas.

\section{Reagentes, soluções e amostras}

Todos os reagentes utilizados foram de grau analítico e as soluções foram preparadas em água deionizada. O TCN 95\% foi adquirido da sigma-aldrich (USA) e utilizado sem purificação adicional. O $\mathrm{AgNO}_{3}$ 99,5\% e o cloreto de sódio ( $\left.\mathrm{NaCl}\right) 99 \%$ foram adquiridos da Quimex (Brasil). A solução estoque de $\mathrm{AgNO}_{3} \approx 5,00 \times 10^{-2} \mathrm{~mol}$ $\mathrm{L}^{-1}$ foi preparada dissolvendo-se uma massa adequada deste sal em água deionizada sendo, em seguida, padronizada por titulação de precipitação com $\mathrm{NaCl}$. As cápsulas contendo TCN $(500 \mathrm{mg})$ foram adquiridas em comércio local.

\section{Titulação condutométrica}

Diferentes alíquotas $(100-2000 \mu \mathrm{L})$ da solução estoque $5,00 \mathrm{x}$ $10^{-2} \mathrm{~mol} \mathrm{~L}^{-1}$ de TCN foram transferidas para um balão volumétrico de $100 \mathrm{~mL}$ e o volume completado com água deionizada. Após homogeneização, a solução contendo TCN foi transferida para um béquer de $150 \mathrm{~mL}$ e, em seguida, introduziu-se neste béquer a célula condutométrica (previamente calibrada). Titulou-se a solução contendo cloridrato de tetraciclina com solução padrão de $\mathrm{AgNO}_{3}$, adicionando-se incrementos de 0,5 ou $0,2 \mathrm{~mL}$ do titulante. $\mathrm{O}$ valor da condutância obtida experimentalmente foi corrigido em função do volume de titulante adicionado de acordo com a Equação 1.

$$
\mathrm{L}_{\text {cor }}=\mathrm{L}_{\exp }\left(\frac{\mathrm{V}_{\mathrm{i}}+\mathrm{V}_{\mathrm{a}}}{\mathrm{V}_{\mathrm{i}}}\right)
$$

sendo: $\mathrm{L}_{\text {cor }}$ a condutância corrigida; $\mathrm{L}_{\exp }$ condutância experimental; $\mathrm{V}_{\mathrm{i}}$ volume inicial; e $\mathrm{V}_{\mathrm{a}}$ volume adicionado.

Por meio do gráfico de condutância corrigida vs o volume de solução de $\mathrm{AgNO}_{3}$, determinou-se o volume do ponto final e, em seguida, a concentração de TCN nas soluções padrão e nas formulações farmacêuticas.

\section{Quantificação de cloridrato de tetraciclina em amostras comerciais utilizando-se a titulação condutométrica}

Oito cápsulas de cada amostra comercial tiveram o seu conteúdo pesado e homogeneizado. Para a análise, foi utilizada uma massa de aproximadamente $50 \mathrm{mg}$ da amostra que, em seguida, foi transferida para um balão volumétrico de $100 \mathrm{~mL}$ e o volume completado com água deionizada. Após homogeneização, a solução contendo a amostra foi transferida para um béquer de $150 \mathrm{~mL}$ e, em seguida, introduziu-se neste béquer a célula condutométrica (previamente calibrada). $\mathrm{O}$ sistema foi titulado com solução padrão de $\mathrm{AgNO}_{3}$, adicionando-se incrementos de 0,5 ou $0,2 \mathrm{~mL}$ do titulante.

\section{Quantificação de cloridrato de tetraciclina em amostras comerciais utilizando-se o método espectrofotométrico}

O método espectrofotométrico recomendado pela Farmacopeia Brasileira ${ }^{17}$ foi aplicado como método de comparação ao método proposto utilizando-se a titulação condutométrica. Oito cápsulas de cada amostra comercial tiveram o seu conteúdo pesado e homogeneizado. Preparou-se uma solução a $0,05 \%$ (p/v) da amostra em ácido clorídrico $0,01 \mathrm{~mol} \mathrm{~L}^{-1}$. A solução padrão de cloridrato de tetraciclina foi preparada na mesma concentração, utilizando-se o mesmo solvente. Diluiu-se $300 \mu \mathrm{L}$ de cada solução para $10 \mathrm{~mL}$ com hidróxido de sódio $0,25 \mathrm{~mol} \mathrm{~L}^{-1} \mathrm{e}$, após homogeneização, as soluções ficaram em repouso por 6 minutos. O branco foi preparado diluindo-se $300 \mu \mathrm{L}$ de ácido clorídrico $0,01 \mathrm{~mol} \mathrm{~L}^{-1}$ para $10 \mathrm{~mL}$ com hidróxido de sódio $0,25 \mathrm{~mol} \mathrm{~L}^{-1}$. As absorbâncias das soluções foram medidas em $380 \mathrm{~nm}$, em cubeta de quartzo de caminho optico de 1 $\mathrm{cm}$, utilizando-se o branco para o ajuste do zero. O cálculo para a quantificação de cloridrato de tetraciclina nas cápsulas foi realizado por meio dos valores obtidos das absorbâncias para as soluções do padrão e das amostras.

\section{RESULTADOS E DISCUSSÃO}

\section{Padronização da solução estoque de $\mathrm{AgNO}_{3}$}

A Figura 2 apresenta a curva de titulação condutométrica obtida na padronização da solução estoque de $\mathrm{AgNO}_{3}$ utilizando-se como padrão primário o $\mathrm{NaCl}$.

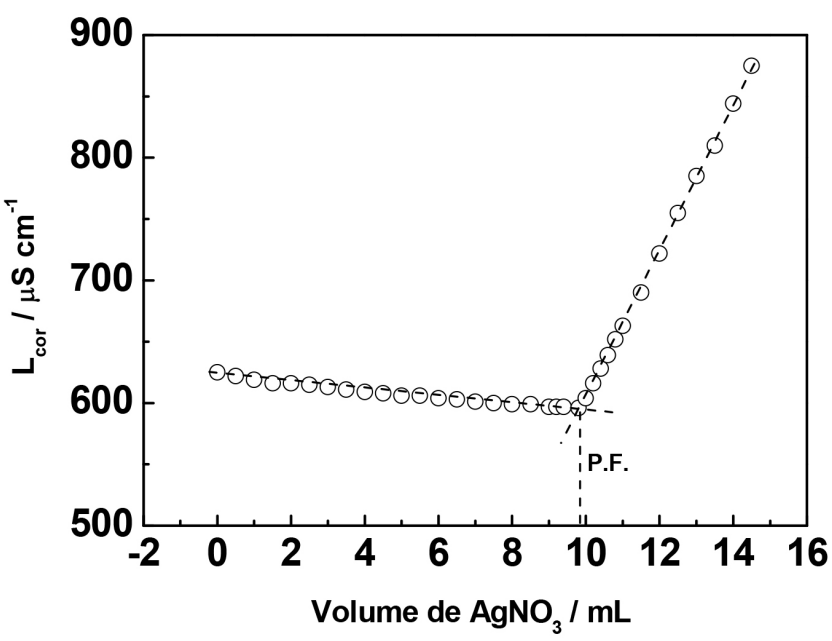

Figura 2. Titulação condutométrica de $100 \mathrm{~mL}$ da solução de $\mathrm{NaCl}$ 5,03 $x$ $10^{-3} \mathrm{~mol} \mathrm{~L}^{-1}$ utilizando-se a solução estoque de $\mathrm{AgNO}_{3}$

A condutância medida antes da adição de $\mathrm{AgNO}_{3}$ se deve aos íons $\mathrm{Na}^{+} \mathrm{e} \mathrm{Cl}^{-}$presentes na cela condutométrica. Até o ponto final, a titulação envolve a precipitação dos íons $\mathrm{Cl}^{-} \operatorname{com~} \mathrm{Ag}^{+}\left(\mathrm{Na}^{+}{ }_{(\text {aq })}+\right.$ $\mathrm{Cl}_{(\text {aq) }}^{-}+\mathrm{Ag}_{(\text {aq) }}^{+}+\mathrm{NO}_{3_{(\mathrm{aq})}^{-}}^{-} \rightarrow \mathrm{AgCl}_{(\mathrm{s})}+\mathrm{Na}_{(\mathrm{aq})}^{+}+\mathrm{NO}_{3_{(\mathrm{aq})}^{-}}^{-}$, que possui uma solubilidade baixa $\left(1,3 \times 10^{-5} \mathrm{~mol} \mathrm{~L}^{-1}\right.$, a $25^{\circ} \mathrm{C}$ e $\left.\mu=0\right)$. Como a condutância do $\mathrm{NO}_{3}{ }^{-}$é um pouco menor do que a de $\mathrm{Cl}^{-}$, até que 
Tabela 1. Comparação entre as concentrações conhecidas de cloridrato de tetraciclina nas soluções padrão e aquelas determinadas empregando-se o método condutométrico

\begin{tabular}{cccc}
\hline Solução padrão de $\mathrm{AgNO}_{3}\left(\mathrm{~mol} \mathrm{~L}^{-1}\right)$ & Solução padrão de TCN $\left(\mathrm{mol} \mathrm{L}^{-1}\right)$ & Experimental de TCN $\left(\mathrm{mol} \mathrm{L}^{-1}\right)^{\text {a }}$ & Erro relativo $(\%)$ \\
\hline $5,11 \times 10^{-4}$ & $5,01 \times 10^{-5}$ & n.d. & - \\
$1,02 \times 10^{-3}$ & $1,00 \times 10^{-4}$ & $9,81 \times 10^{-5} \pm 6,23 \times 10^{-7}$ & $-2,08$ \\
$5,11 \times 10^{-3}$ & $5,01 \times 10^{-4}$ & $5,10 \times 10^{-4} \pm 2,97 \times 10^{-7}$ & 1,78 \\
$1,02 \times 10^{-2}$ & $1,00 \times 10^{-3}$ & $1,01 \times 10^{-3} \pm 2,94 \times 10^{-7}$ & 0,51 \\
\hline
\end{tabular}

n.d. Ponto final da titulação condutométrica não detectado; ${ }^{a}$ média \pm desvio padrão para três determinações.

o ponto final seja alcançado, observa-se uma pequena variação na condutância com a substituição do íon $\mathrm{Cl}^{-}$pelo íon $\mathrm{NO}_{3}^{-}$. Após o ponto final, a condutância aumenta devido ao excesso de íons $\mathrm{Na}^{+} \mathrm{e}$ $\mathrm{NO}_{3}{ }^{-}$. O volume do ponto final (PF) foi determinado pela interseção das retas extrapoladas.

Utilizando-se a titulação condutométrica na padronização da solução estoque de $\mathrm{AgNO}_{3}$ obteve-se uma concentração de 5,11 x 10-2 $\pm 1,96 \times 10^{-4} \mathrm{~mol} \mathrm{~L}^{-1}(\mathrm{n}=3)$. O método de Mohr também foi empregado na padronização da solução estoque de $\mathrm{AgNO}_{3}$ obtendo-se uma concentração de $5,06 \times 10^{-2} \pm 5,92 \times 10^{-4} \mathrm{~mol} \mathrm{~L}^{-1}(\mathrm{n}=3)$. O teste $\mathrm{f}$ foi aplicado para comparar as precisões obtidas empregando-se ambos os métodos, resultando em um valor de f calculado $(9,12)$ menor que o valor de f tabelado $(19,0)$, indicando que não existe diferença significativa entre as precisões destes dois métodos, em um nível de confiança de $95 \%$, o que possibilitou a aplicação do teste t. O valor de $t$ calculado $(1,391)$ foi menor que o t tabelado $(4,303)$, indicando que não existe uma diferença significativa, em um nível de confiança de $95 \%$, entre as médias dos resultados obtidos pelos dois métodos.

\section{Estudos preliminares}

Após a padronização da solução estoque de $\mathrm{AgNO}_{3}$ realizaram-se três titulações condutométricas sucessivas de solução de TCN com concentrações variando de 5,01 x $10^{-5}$ a 1,00 x $10^{-3} \mathrm{~mol} \mathrm{~L}^{-1}$, utilizando-se como titulante solução padrão de $\mathrm{AgNO}_{3}$ com concentrações variando de $5,11 \times 10^{-4}$ a $1,02 \times 10^{-2} \mathrm{~mol} \mathrm{~L}^{-1}$, como apresentado na Tabela 1.

Para a concentração de TCN de $5,01 \times 10^{-5} \mathrm{~mol} \mathrm{~L}^{-1}$ a adição de $\mathrm{AgNO}_{3} 5,11 \times 10^{-4} \mathrm{~mol} \mathrm{~L}^{-1}$ não ocasionou variações significativas de condutância, dificultando a determinação do ponto final da titulação condutométrica. Isso ocorre devido à diluição das soluções e à solubilidade do $\mathrm{AgCl}$ formado. Observa-se uma boa concordância entre as concentrações de TCN determinadas condutometricamente e as concentrações das soluções padrão. Para a quantificação de TCN em formulações farmacêuticas, optou-se por utilizar as concentrações do titulante $\mathrm{AgNO}_{3}$ de $1,02 \times 10^{-2} \mathrm{~mol} \mathrm{~L}^{-1}$ e de TCN de $1,00 \times 10^{-3} \mathrm{~mol} \mathrm{~L}^{-1}$, pois nessas concentrações obteve-se um menor erro relativo $(0,51 \%)$.
A Figura 3 apresenta a curva de titulação condutométrica obtida para a determinação da concentração de TCN na solução padrão empregando-se $\mathrm{AgNO}_{3} 1,02 \times 10^{-2} \mathrm{~mol} \mathrm{~L}^{-1}$ como titulante.

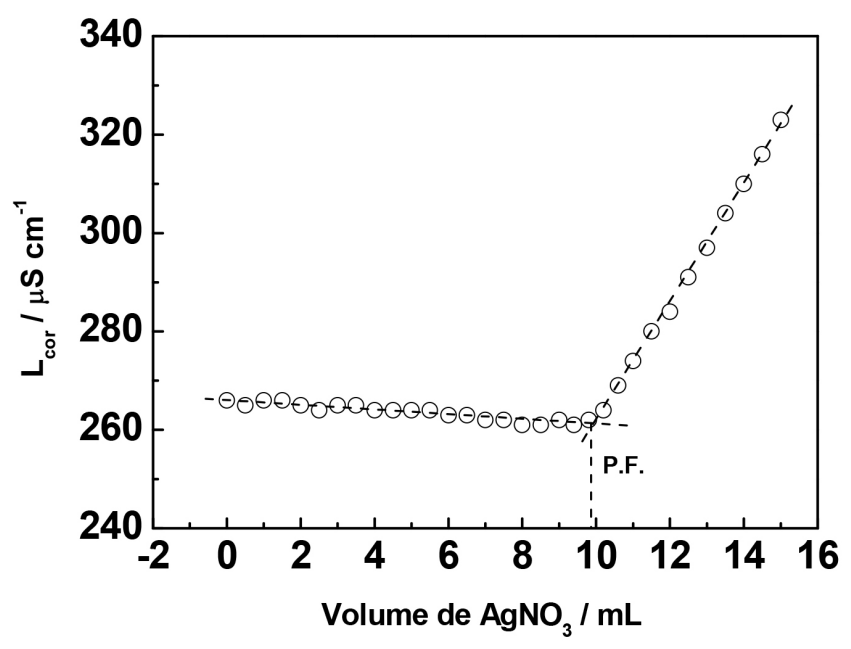

Figura 3. Titulação condutométrica de $100 \mathrm{~mL}$ da solução de cloridrato de tetraciclina 1,00 $\times 10^{-3} \mathrm{~mol} \mathrm{~L}^{-1}$ utilizando-se a solução de $\mathrm{AgNO}_{3} 1,02 \times$ $10^{-2} \mathrm{~mol} \mathrm{~L}^{-1}$

A condutância medida antes da adição de $\mathrm{AgNO}_{3}$ se deve à molécula de TCN presente na célula condutométrica. Até o ponto final, a titulação envolve a formação do precipitado de $\mathrm{AgCl}$ (Figura 4). Esperava-se uma inclinação maior no primeiro ramo da curva condutométrica, devido à alta condutividade iônica dos íons $\mathrm{H}_{3} \mathrm{O}^{+}$, no entanto, os íons $\mathrm{H}_{3} \mathrm{O}^{+}$podem estar protonando os grupos amino da molécula de TCN, acarretando na diminuição da inclinação do primeiro ramo da curva da titulação condutométrica. Esta pequena inclinação pode ser atribuída à pequena concentração de íons $\mathrm{H}_{3} \mathrm{O}^{+}$ livres na solução e também ao aumento da concentração dos íons $\mathrm{NO}_{3}^{-}$do titulante, com condutância menor que a dos íons $\mathrm{Cl}^{-}$. Após o ponto final, a condutância aumenta devido ao excesso da solução<smiles>C[C@@H]1C(O)=C2C(C[C@@H]1N(C)C)C(=O)c1c(O)cccc1C(O)(O)[C@H]2C</smiles>

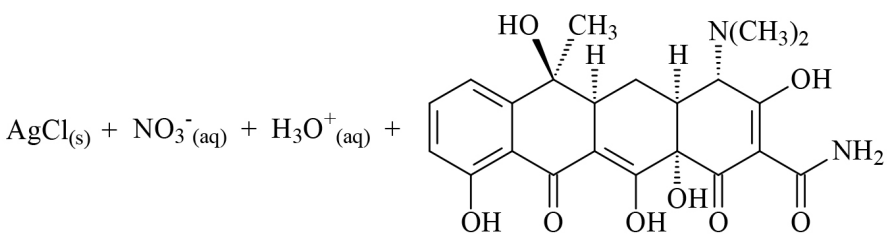

Figura 4. Reação química da titulação condutométrica do cloridrato de tetraciclina com a solução padronizada de $\mathrm{AgNO}_{3}$ 
de $\mathrm{AgNO}_{3}$ adicionado. $\mathrm{O}$ volume do ponto final (PF) foi determinado pela interseção dos dois segmentos lineares.

\section{Estudos de repetitividade, interferentes e recuperação}

No estudo de repetitividade do procedimento condutométrico, uma solução de TCN $1,00 \times 10^{-3} \mathrm{~mol} \mathrm{~L}^{-1}$ foi titulada por seis vezes ( $\mathrm{n}=6$ ) com solução de $\mathrm{AgNO}_{3} 1,02 \times 10^{-2} \mathrm{~mol} \mathrm{~L}{ }^{-1}$, obteve-se um coeficiente de variação de $0,64 \%$.

Não foi realizado o estudo de interferentes, pois os excipientes (estearato de magnésio, amidoglicolato de sódio, laurilsulfato de sódio, crospovidona e talco) encontrados nas formulações farmacêuticas contendo TCN são insolúveis e/ou possuem baixa solubilidade, portanto, estes excipientes não são interferentes em potencial. No entanto, é importante ressaltar que sais de haletos são interferentes em amostras contendo essas espécies químicas.

O estudo de recuperação foi feito com três massas diferentes de padrão de $\mathrm{TCN}(\approx 5,10$ e $20 \mathrm{mg}$ ) adicionadas a duas amostras de formulações farmacêuticas (referência e genérico) com dosagem de $500 \mathrm{mg}$ de TCN por comprimido. Os resultados foram comparados com aqueles obtidos com as amostras não fortificadas. Os resultados obtidos no estudo de recuperação são apresentados na Tabela 2. Observa-se que as recuperações variaram de 99,0 a $105 \%$, confirmando que não há interferência significativa da matriz (excipientes) nas amostras de formulações farmacêuticas analisadas.

Tabela 2. Estudo de recuperação de cloridrato de tetraciclina em formulações farmacêuticas

\begin{tabular}{lccc}
\hline \multirow{2}{*}{ Amostra } & \multicolumn{2}{c}{ Massa de TCN $(\mathrm{mg})$} & \multirow{2}{*}{$\begin{array}{c}\text { Recuperação } \\
(\%)\end{array}$} \\
\cline { 2 - 3 } & Adicionada & Determinada & 105 \\
\multirow{3}{*}{ Referência } & 5,21 & 5,46 & 103 \\
& 10,01 & 10,32 & 100 \\
\hline \multirow{3}{*}{ Genérico } & 20,08 & 20,17 & 104 \\
& 5,18 & 5,37 & 99,0 \\
& 10,00 & 9,87 & 99,0 \\
\hline
\end{tabular}

\section{Aplicações}

O método condutométrico proposto foi aplicado na determinação de TCN em duas formulações farmacêuticas (referência e genérico) e os resultados foram comparados com aqueles obtidos empregando-se o método espectrofotométrico (recomendado pela Farmacopeia Brasileira) ${ }^{17}$ e com os valores descritos nos rótulos.

A Figura 5 apresenta a curva de titulação condutométrica obtida para a determinação da concentração de TCN na amostra de formulação farmacêutica de referência empregando-se $\mathrm{AgNO}_{3}$ $1,02 \times 10^{-2} \mathrm{~mol} \mathrm{~L}^{-1}$ como titulante. Observa-se que a curva de titulação condutométrica para a formulação farmacêutica de referência é muito

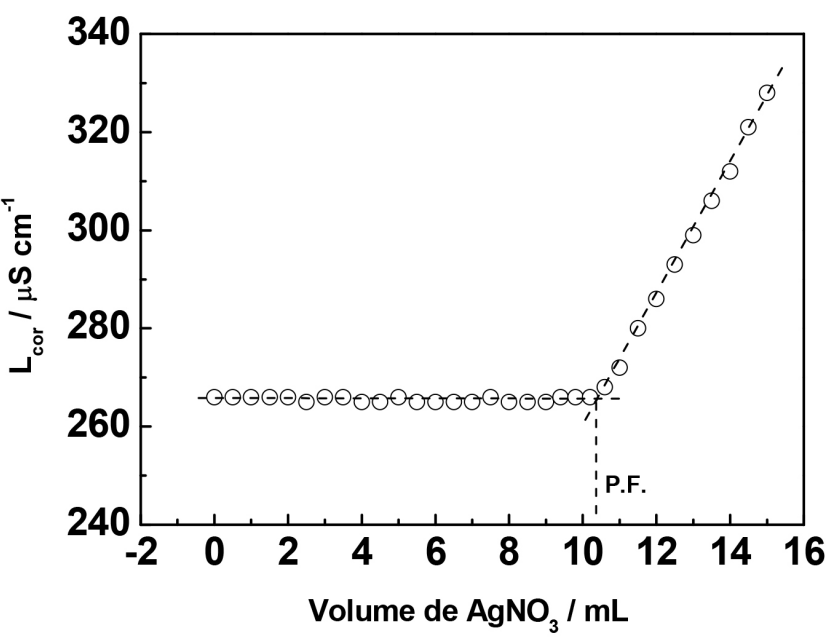

Figura 5. Titulação condutométrica de formulação farmacêutica de referência contendo cloridrato de tetraciclina utilizando-se a solução de $\mathrm{AgNO}_{3}$ 1,02 $x 10^{-2} \mathrm{~mol} \mathrm{~L}^{-1}$

semelhante à curva obtida para a solução padrão de TCN.

A Tabela 3 apresenta os resultados obtidos nas análises de TCN em formulações farmacêuticas empregando-se o método espectrofotométrico recomendado pela Farmacopeia Brasileira e a titulação condutométrica.

O teste $\mathrm{f}$ foi aplicado para comparar as precisões obtidas empregando-se os métodos espectrofotométrico e de titulação condutométrica, resultando em valores de $\mathrm{f}$ calculados menores que o valor de $\mathrm{f}$ tabelado $(19,0)$ para as duas amostras de formulações farmacêuticas (referência e genérico), indicando que não existe diferença significativa entre as precisões dos dois métodos empregados, em um nível de confiança de $95 \%$, possibilitando a aplicação do teste t. Os valores de t calculados (2,190 - referência; 1,643 - genérico) são menores que o t tabelado $(4,303)$, indicando que não existem diferenças significativas, em um nível de confiança de $95 \%$, entre as médias dos resultados dos dois métodos para as duas formulações farmacêuticas analisadas.

\section{CONCLUSÃO}

O método proposto para a quantificação de TCN em formulações farmacêuticas, utilizando-se a titulação condutométrica e o $\mathrm{AgNO}_{3}$ como titulante, mostrou-se simples, preciso, rápido e de baixo custo, quando comparado com outros métodos analíticos. Além disso, outro aspecto importante do método proposto é o fato de não necessitar de nenhum tipo de tratamento complexo da amostra, possibilitando sua aplicação na quantificação de TCN em laboratórios de análise de rotina.

\section{AGRADECIMENTOS}

Ao apoio financeiro da Universidade Católica de Brasília (UCB).

Tabela 3. Resultados obtidos nas análises de cloridrato de tetraciclina em formulações farmacêuticas empregando-se o método espectrofotométrico recomendado pela Farmacopeia Brasileira e a titulação condutométrica

\begin{tabular}{lccccc}
\hline \multirow{2}{*}{ Amostras } & \multicolumn{2}{c}{ TCN $\left(\mathrm{mg}\right.$ comprimido $\left.{ }^{-1}\right)$} & \multicolumn{2}{c}{ Erro relativo (\%) } \\
\cline { 2 - 6 } & Rótulo & Método espectrofotométrico ${ }^{\mathrm{a}}$ & Titulação condutométrica $^{\mathrm{a}}$ & $\mathrm{ER}_{1}{ }^{\mathrm{b}}$ & $\mathrm{ER}_{2}{ }^{\mathrm{c}}$ \\
\hline Referência & 500 & $505 \pm 3$ & $509 \pm 1$ & 0,79 & 1,80 \\
Genérico & 500 & $507 \pm 3$ & $510 \pm 1$ & 0,59 & 2,00 \\
\hline
\end{tabular}

${ }^{\mathrm{a}} \mathrm{n}=3 ;{ }^{\mathrm{b}} \mathrm{ER}_{1}=[($ titulação condutométrica - método espectrofotométrico $) /$ método espectrofotométrico $] \times 100 ;{ }^{\mathrm{c}} \mathrm{ER}_{2}=[($ titulação condutométrica - valor no rótulo)/ valor no rótulo] x 100 . 


\section{REFERÊNCIAS}

1. Gholivand, M. B.; Khani, H.; Electroanalysis 2013, 25, 461.

2. Wong, A.; Scontri, M.; Materon, E. M.; Lanza, M. R. V.; Sotomayor, M. D. P. T.; J. Electroanal. Chem. 2015, 757, 250.

3. Divya, M. P.; Rajput, Y. S.; Sharma, R.; Anal. Lett. 2010, 43, 919.

4. Wang, Y.; Xu, X. H.; Han, J.; Yan, Y. S.; Desalination 2011, 266, 114.

5. Yang, X.; Luo, Y.; Zhu, S.; Feng, Y.; Zhuo, Y.; Dou, Y.; Biosens. Bioelectron. 2014, 56, 6 .

6. Leng, F.; Zhao, X. J.; Wang, J.; Li, Y. F.; Talanta 2013, 107, 396.

7. Tolgyesi, A.; Tolgyesi, L.; Bekesi, K.; Sharma, V. K.; Fekete, J.; Meat Sci. 2014, 96, 1332.

8. Shalaby, A. R.; Salama, N. A.; Abou Raya, S. H.; Emam, W. H.; Mehaya, F. M.; Food Chem. 2011, 124, 1660.

9. Yang, X. Q.; Yang, C. X.; Yan, X. P.; J. Chromatogr. A, 2013, 1304, 28.

10. Mu, G.; Liu, H.; Xu, L.; Tian, L.; Luan, F.; Food Anal. Methods 2012, $5,148$.

11. Ma, T. Y.; Vickroy, T. W.; Shien, J. H.; Chou, C. C.; Electrophoresis 2012, 33, 1679.

12. Cunha, C. O.; Silva, R. C. R.; Amorim, C. G.; Junior, S. A.; Araujo, A. N.; Montenegro, M. C.; Silva, V. L.; Electroanalysis 2010, 22, 2967.

13. Moreira, F. T. C.; Kamel, A. H.; Guerreiro, J. R. L.; Sales, M. G. F.; Biosens. Bioelectron. 2010, 26, 566.

14. Calixto, C. M. F.; Cervini, P.; Cavalheiro, E. T. G.; J. Braz. Chem. Soc. 2012, 23, 938.
15. Zhan, X.; Hu, G.; Wagberg, T.; Zhan, S.; Xu, H.; Zhou, P.; Microchim Acta 2016, 183, 723.

16. Kushikawa, R. T.; Silva, M. R.; Angelo, A. C. D.; Teixeira, M. F. S.; Sens. Actuators, B 2016, 228, 207.

17. Farmacopeia Brasileira, Agência Nacional de Vigilância Sanitária: Brasília, 2010, p. 863.

18. Sartori, E. R.; Suarez, W. T.; Fatibello-Filho, O.; Anal. Lett. 2009, 42, 659.

19. Sartori, E. R.; Suarez, W. T.; Fatibello-Filho, O.; Quim. Nova 2009, 32, 1947.

20. Caetano, F. R.; Gevaerd, A.; Bergamini, M. F.; Marcolino-Junior, L. H.; Curr. Pharm. Anal. 2011, 7, 275.

21. Riad, S. M.; Anal. Bioanal. Electrochem. 2013, 5, 99.

22. Rossini, P. O.; Felix, F. S.; Angnes, L.; Cent. Eur. J. Chem. 2012, 10, 1842.

23. Janegitz, B. C.; Suarez, W. T.; Fatibello-Filho, O.; Marcolino-Junior, L. H.; Anal. Lett. 2008, 41, 3264.

24. Hassan, W. S.; Mervat, M. H.; E-J. Chem. 2008, 5, 1069.

25. Sartori, E. R.; Barbosa, N. V.; Faria, R. C.; Fatibello- Filho, O.; Ecl. Quím. 2011, 36, 110.

26. Lourenção, B. C.; Marcolino-Junior, L. H.; Fatibello-Filho, O.; Quim. Nova 2008, 31, 349.

27. Elwy, H. M.; Abdel-Moaty, M. M.; Abdel-Hamid, S. M.; Anal. Bioanal. Electrochem. 2015, 7, 105. 